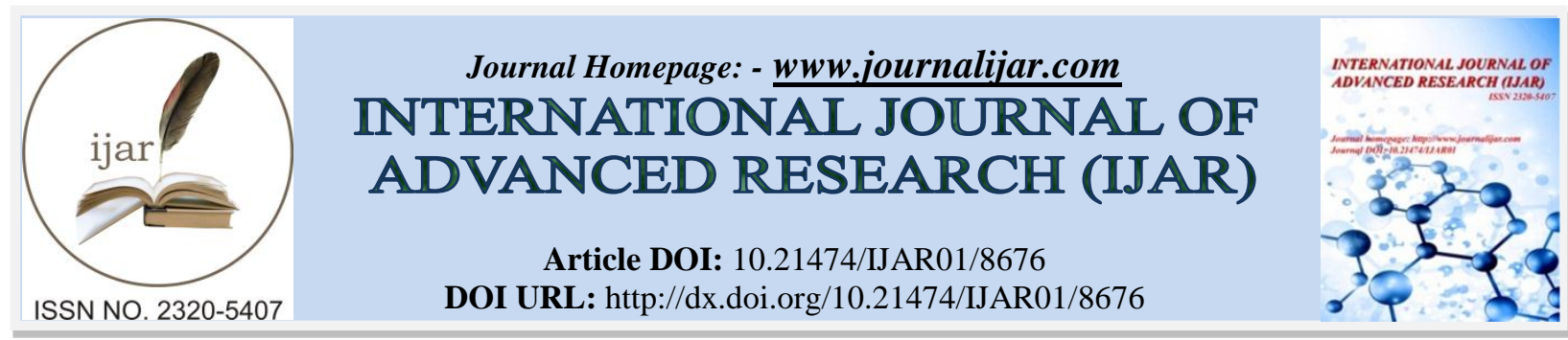

RESEARCH ARTICLE

\title{
NON-PEDICLED BUCCAL FAT PAD GRAFT VERSUS CONNECTIVE TISSUE GRAFT IN MANAGEMENT OF GINGIVAL RECESSIONS USING VESTIBULAR INCISION SUBPERIOSTEAL TUNNEL ACCESS TECHNIQUE.
}

Ahmed Abdallah Khalil.

Lecturer of Oral Medicine, Oral Diagnosis and Periodontology, Faculty of Dentistry, Minia University, Egypt.

\section{Manuscript Info}

Manuscript History

Received: 12 January 2019

Final Accepted: 14 February 2019

Published: March 2019

Key words:-

Non-pedicled buccal fat pad graft (NPBFP), subepithelial connective tissue graft (SCTG) gingival recessions (GRs), vestibular incision subperiosteal tunnel access technique (VISTA)

\section{Abstract}

Aim of study: To assess effect of non-pedicled buccal fat pad graft (NPBFP) versus subepithelial connective tissue graft (SCTG) in management of of gingival recessions (GRs) using vestibular incision subperiosteal tunnel access technique (VISTA).

Patients and methods: Twenty patients with Miller Class I or II (GRs) recessions were randomly assigned to receive SCTG (group I) or NPBFP (groupII) using (VISTA) technique. The clinical parameters evaluated at baseline, 3 and 6 months postoperatively included gingival index (GI), plaque index (PI), clinical attachment level (CAL), and gingival recessions (GRs).

Results: Both groups exhibited statistically significant differences in all clinical parameters when compering baseline to 3 and 6 months after surgery. Upon comparing the results of both groups, no statistically significant difference was detected regarding all clinical parameters. However, there was more improvement in group I than group II.

Conclusion: The results presented indicate that both NPBFP and SCTG considered as clinically successful methods for treating Miller Class I and Class II GRs.

Copy Right, IJAR, 2019,. All rights reserved.

\section{Introduction:-}

Gingival recession is defined as apical migration of the gingival margin beyond the cemento-enamel junction (CEJ) [The American Academy of Periodontology, 2001].Gingival recession is a common clinical condition resulting in dentinal hypersensitivity, pain, carious and non-carious lesions, poor esthetics and plaque retention. There are various anatomic, pathologic, physiological and iatrogenic factors causing recession. It may be caused by periodontal disease, improper or aggressive tooth brushing, inflammation or occlusal discrepancies [Reddy $\mathbf{S}$ et al., 2013].

The treatment of recession defects associated with multiple teeth poses greater challenge to clinician as avascular root surface area is more extensive. Also, thin biotype, decreased keratinized tissue width (KTW), root prominence and root proximity make the choice of surgical treatment difficult as compared to localized gingival recession type defects. Different tunnel techniques that can maintain the better blood supply and maintain critical papillary integrity have been attempted for management of recession defects. However, these procedures are technique sensitive and tissue trauma to sulcular epithelium which may lead to unfavorable healing outcomes as reported in some studies 
[Zadeh HH, 2011]. To avoid these complications in treatment procedures, minimal invasive technique, the vestibular incision subperiosteal tunnel access (VISTA) approach was introduced [Divyanshu Jamwal et al., 2017]. Subepithelial Connective tissue graft (SCTG) technique is the most commonly used free soft tissue graft showing predictable and reproducible results in root coverage. Thus, it is considered as a gold standard though it has its own limitations which include the need of a second surgical site and technique sensitive procedure [Zadeh HH, 2011]. The use of coronally advanced flap with acellular dermal matrix derivative, emdogain, and collagen matrix, platelet rich fibrin also provide good results, many of them similar to SCTG-based procedures, and thus these may be considered as adequate substitute treatment approaches [Jankovic $\mathbf{S}$ et al., 2012].

Other treatment modalities of GRs include non-pedicled buccal fat pad graft (NPBFP) and pedicled buccal fat pad graft (PBFP). The buccal fat pad (BFP) is a specially organized adipose tissue, composed of a specialized type of fat termed syssarcosis, a fat that enhances intermuscular motion and not subjected to lipolysis. The use of PBFP in maxillary molars recessions offers advantages in the root coverage of such defects. The proximity of the donor site to the recipient bed and the accessibility can prove advantageous. Moreover, it has also been reported with minimal donor site morbidity and patient discomfort. The PBFP has a rich plexus of blood vessels forming an internal microvascular network that ensures the survival of the flap after relocation [Saurav Panda et al., 2016]. It can be used for various surgical site oral reconstruction needs such as closure of palatal defects, oro-antral fistulas, postextraction defects, and temporomandibular joint reconstruction. In addition, it can be used as a membrane in sinus augmentation. Moreover, it can be used for root coverage procedures, particularly in the posterior maxilla [Singh J et al., 2010].

The review of dental and maxillofacial surgery literature revealed only a few publications considering the use of the NPBF. The NPBFP improved the clinical attachment level of soft tissue around the affected implants and their survival, with excellent functional and esthetic outcomes of the treated implants. The fibrotic healing of the BFFG inhibited the recurrence of the peri-implant lesions [Kablan F, 2015].

De Castro et al., in 2015 in their case report, described the use of BFP as a free graft for closure of oronasal fistula and suggested it as a treatment option for some cases of anterior maxillary defects [de Castro CH et al., 2015]. So in this study, we assessed the effect of non pedicled buccal fat pad versus subepithelial connective tissue graft in management of gingival recession class I and II using VISTA technique.

\section{Patients and Methods}

This study was conducted on $\mathbf{2 0}$ patients who suffered from either Miller class I or class II multiple gingival recession.The entire patients were selected from the out patients clinic of the Oral Medicine, Oral Diagnosis, and Periodontology Department. Faculty of Dentistry, Minia University.

\section{(I) Ethical regulations:}

The complete treatment plan was explained to all patients including detailed steps, risks, and expected results and their full signed consent was obtained prior to entry into the study. The study was complied with the rules set by the International Conference on Harmonization Good Clinical Practice Guidelines, and the Declaration of Helsinki an the research ethics committee of the Faculty of Dentistry, Mini University.

\section{(II) Patient selection:}

Selected patients of both sexes were 25-48 years old, Patients were systemically healthy based on questionnaire dental modification of Cornell index., Buccal recession defects were classified as Miller Class I or II according to Miller's classification [Miller PD Jr, 1985]. Patients were free from any systemic diseases that might influence their periodontal condition and had not undergone any type of regenerative periodontal therapy six months prior to the initial examination. On the other hand Pregnant, lactating females and smokers were excluded from the study.

\section{(III)Treatment protocol:}

All patients underwent phase I therapy comprising of full mouth mechanical debridement and instructed for routine oral hygiene measures. The Twenty patients were divided into two groups, randomly selected for treatment with group I subepithelial connective tissue graft (SCTG) and group II Non-pedicled buccal fat pad (NPBFP). The VISTA (vestibular incision subperiosteal tunnel access) approach using VISTA TUNNELING KIT (ARTMAN insturments, USA) was begun with a vestibular access incision mesial to the defect (Fig.1 A,B) which provided access to the entire defect, Subperiosteal tunnel was created by passing the incision through the periosteum and 
inserting the different periosteal elevators of VISTA kit between the periosteum and bone through the vestibular access incision. To mobilize gingival margins and facilitate coronal repositioning, the tunnel was extended at least one or two teeth beyond the teeth requiring root coverage. In order to achieve a low-tension coronal repositioning of the gingiva, the tunnel was sufficiently elevated beyond the mucogingival junction as well as through the gingival sulci of the teeth being augmented.

Regarding group I (the group treated with SCTG), connective tissue graft was obtainned by incsion placed between the distal aspect of the first premolar and the distal aspect of the first molar with a single incsion technique as given by Hürzeler and Weng in 1999 [Hürzeler MB, Weng D, 1999]. A SCTG with 2mm thickness was harvested (Fig 2 A, B), trimmed and prepared for grafting and the donor area was closed by primary closure using non-resorbable 4-0 surgical black silk suture.

For group II (the group treated with NPBFP), Prior to harvesting NPBFP, a terminal infiltration anesthetic was injected into the region of the upper first and second molars at the intended BFPG recipient site. A horizontal incision measuring $1.5 \mathrm{~cm}$ was made at the bottom of the vestibule, in the region of the maxillary right or left first and second molars, depending on which side the surgery was performed. A curved hemostat was used to reposition temporarily the muscles at the relevant location, in order to expose the adipose tissue, and adipose tissue was then removed (Fig.3 A, B) then the donor site was immediately sutured. The roots of the recipient teeth cheked well for any subgingival debosits or calculas and conditiond by using EDTA gel before graft application and any odontoplasty needed was done.

NPBFPG or SCTG was placed into the subperiosteal tunnel through the vestibular access incision, and then the flap was advanced coronally at the CEJ level and fixed at the new position by 5-0 absorbable suture and flowable composite stops at the mid coronal point of each tooth (Fig. 4 A, B). The access incisions were closed with interrupted sutures.

Patients were advised to rinse with chlorohexidine digluconate mouth rinse $0.12 \%$ twice daily for 2 weeks, Anti inflammatory Ibuprofen (Brufen ${ }^{\circledR}$, Abbott, Egypt) 400mg 3 times daily as necessary and antibiotic (Augmentin)( GlaxoSmithKline, Egypt)(Amoxicillin+ clavulenic acid $1 \mathrm{gm}$ for 8 days) were prescribed for all patients. The sutures were removed 14 days after surgery.

\section{(IV) Assessment method:}

Follow up visits were performed to all patients at regular basis at baseline (prior to surgery), 3 and 6 months after surgery. The measures of the clinical parameters were assessed by the following parameters Using UNC.15 probe including Gingival Index (GI), Plaque Index (PI),), Clinical attachment level (CAL), Gingival Recession Depth (GR).
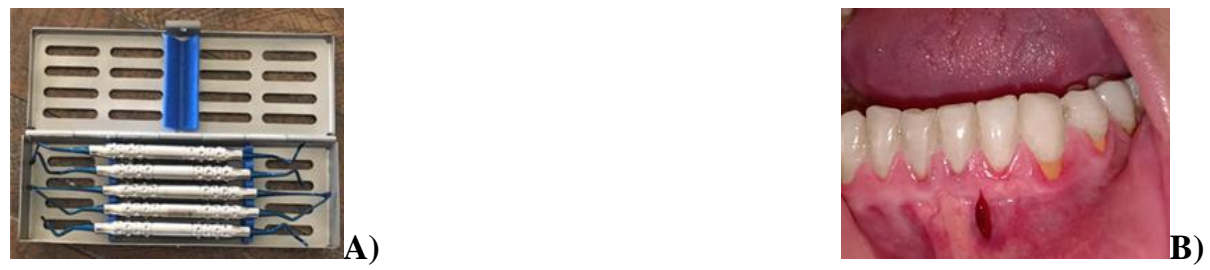

(Fig. 1) A. VIST KIT, B. Vestibular access incision mesial to the defect
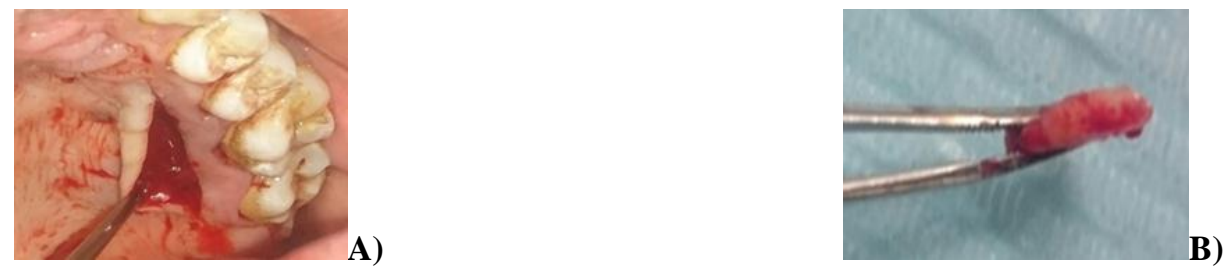

Fig. 2 (A). Single incsion technique for SCTG harvestig, (B). SCTG with $2 \mathrm{~mm}$ thickness 


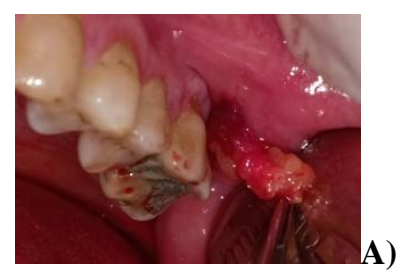

Fig. 3 (A).Harvesting NPBFP, (B).NPBFP graft

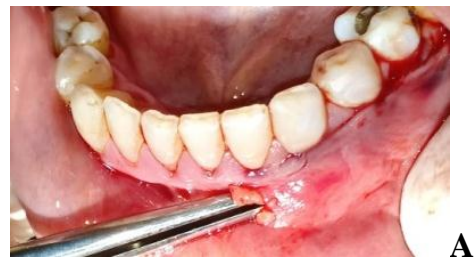

A)

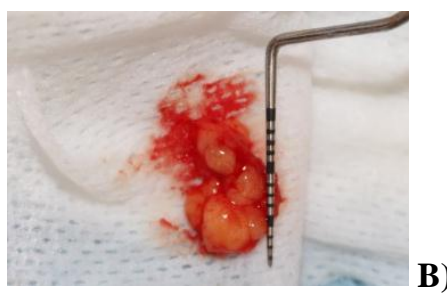

B)

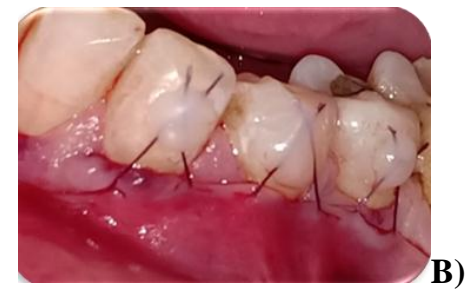

Fig. 4 (A).Inserion of NPBFPG or SCTG into the subperiosteal tunnel through the vestibular access incision, (B). The flap was advanced coronally and fixed with flowable composite.
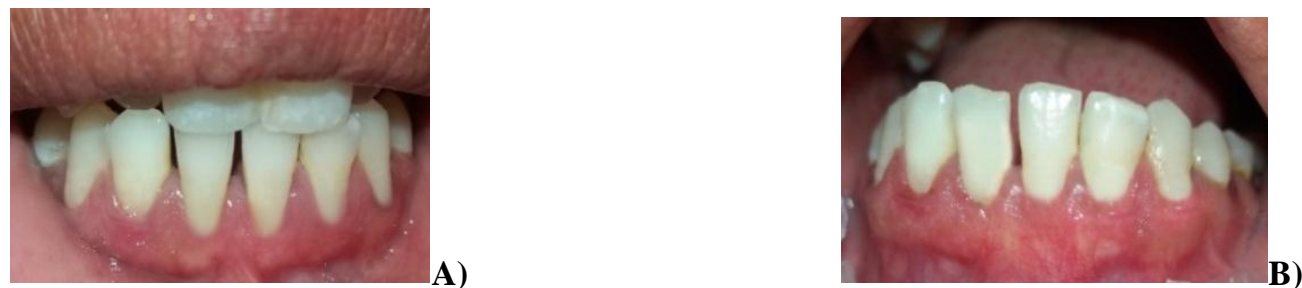

Fig. 5 (A). Case SCTG group at baseline (B). Case SCTG group after 6 months
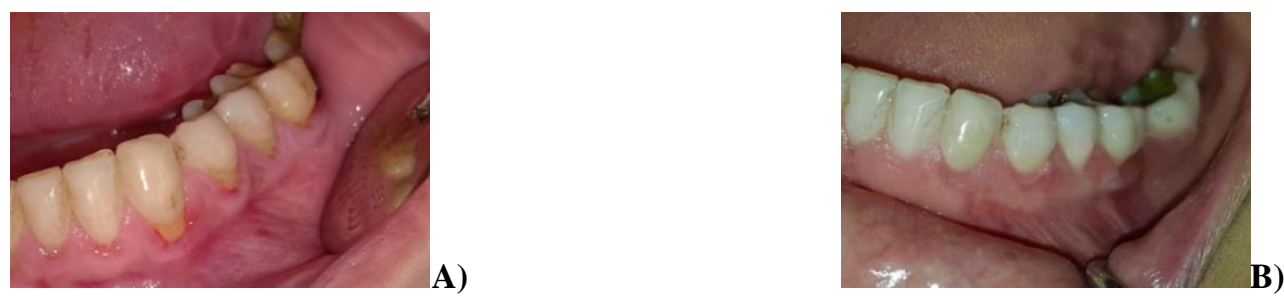

Fig. 6 (A).Case NPBFP group at baseline (B). Case NPBFP group after 6months

\section{Results:-}

This study was conducted on 20 patients who suffered from either class I or class II multiple gingival recession of both sexes with ranged age 25-48 years old. The twenty patients were divided into two groups, group I used subepithelial connective tissue graft (SCTG) and group II used Non-pedicled buccal fat pad (NPBFP) for treatment of gingival recession using VISTA technique.

There were no postoperative healing complications, and no patient was excluded from the study after enrolment. None of the evaluated clinical parameters differed significantly between the groups at baseline or at any of the assessed postoperative periods. Comparison of the clinical parameters at different stages of treatment between SCTG and NPBFP are shown in Table 1.

Both groups showed statistically significant differences in GR at 3 and 6 months postoperatively in comparison with baseline and Table 2 and 3 showed comparison of the clinical parameters at baseline, 3 and 6 months after treatment in SCTG and NPBFP groups. 
Table 1:- comparison of the clinical parameters at different stages of treatment between SCTG and NPBFP

\begin{tabular}{|l|l|l|l|}
\hline Parameters & SCTG & NPBFP & p-value \\
\cline { 2 - 4 } & Mean \pm SD & Mean \pm SD & \\
\hline Gingival Recession (GRs) & & & \\
0 & $3.21 \pm 0.61$ & $3.47 \pm 0.50$ & 0.3 \\
3 & $0.92 \pm 0.311$ & $1.24 \pm 0.39$ & 0.06 \\
6 & $0.86 \pm 0.26$ & $1.04 \pm 0.37$ & 0.2 \\
\hline Gingival index (GI) & & & \\
0 & $1.57 \pm 0.40$ & $1.63 \pm 0.31$ & 0.7 \\
3 & $0.38 \pm 0.19$ & $0.44 \pm 0.23$ & 0.5 \\
6 & $0.35 \pm 0.17$ & $0.35 \pm 0.23$ & 0.9 \\
\hline Plaque index (PI) & & & \\
0 & $1.72 \pm 0.36$ & $1.76 \pm .35$ & 0.8 \\
3 & $0.28 \pm 0.16$ & $0.33 \pm 0.27$ & 0.6 \\
6 & $0.23 \pm 0.11$ & $0.25 \pm 0.17$ & 0.7 \\
\hline Clinical attachment level (CAL) & & & \\
0 & $3.66 \pm 1.01$ & $4.01 \pm 0.39$ & 0.3 \\
3 & $1.99 \pm 0.29$ & $2.01 \pm 0.44$ & 0.9 \\
6 & $1.96 \pm 0.36$ & $1.90 \pm 0.53$ & 0.7 \\
\hline
\end{tabular}

Table2: comparison of the clinical parameters at baseline, 3 and 6 months after treatment in SCTG

\begin{tabular}{|l|l|l|l|l|l|}
\hline Parameters & Baseline & $\begin{array}{l}\text { after 3m of } \\
\text { treatment }\end{array}$ & $\begin{array}{l}\text { after 6m of } \\
\text { treatment }\end{array}$ & $\begin{array}{l}\text { P-value } \\
\text { Base VS 3 } \\
\text { months }\end{array}$ & $\begin{array}{l}\text { P-value } \\
\text { Base } \\
\text { 6months }\end{array}$ \\
\hline Gingival Recession (GR) & $3.21 \pm 0.61$ & $0.92 \pm 0.311$ & $0.86 \pm 0.26$ & $<0.0001$ & $<0.0001$ \\
\hline Gingival index (GI) & $1.57 \pm 0.40$ & $0.38 \pm 0.19$ & $0.35 \pm 0.17$ & $<0.0001$ & $<0.0001$ \\
\hline Plaque index (PI) & $1.72 \pm 0.36$ & $0.28 \pm 0.16$ & $0.23 \pm 0.11$ & $<0.0001$ & $<0.0001$ \\
\hline $\begin{array}{l}\text { Clinical attachment level } \\
(\mathrm{CAL})\end{array}$ & $3.66 \pm 1.01$ & $1.99 \pm 0.29$ & $1.96 \pm 0.36$ & 0.002 & 0.002 \\
\hline
\end{tabular}

Table3: comparison of the clinical parameters at baseline, 3 and 6 months after treatment in NPBFP

\begin{tabular}{|l|l|l|l|l|l|}
\hline Parameters & Baseline & $\begin{array}{l}\text { after 3m of } \\
\text { treatment }\end{array}$ & $\begin{array}{l}\text { after 6m of } \\
\text { treatment }\end{array}$ & $\begin{array}{l}\text { P-value } \\
\text { Base VS 3 } \\
\text { months }\end{array}$ & $\begin{array}{l}\text { P-value } \\
\text { Base } \\
\text { 6months }\end{array}$ \\
\hline Gingival Recession (GR) & $3.47 \pm 0.50$ & $1.24 \pm 0.39$ & $1.04 \pm 0.37$ & $<0.0001$ & $<0.0001$ \\
\hline Gingival index (GI) & $1.63 \pm 0.31$ & $0.44 \pm 0.23$ & $0.35 \pm 0.23$ & $<0.0001$ & $<0.0001$ \\
\hline Plaque index (PI) & $1.76 \pm .35$ & $0.33 \pm 0.27$ & $0.25 \pm 0.17$ & $<0.0001$ & $<0.0001$ \\
\hline $\begin{array}{l}\text { Clinical attachment level } \\
(\mathrm{CAL})\end{array}$ & $4.01 \pm 0.39$ & $2.01 \pm 0.44$ & $1.90 \pm 0.53$ & $<0.0001$ & $<0.0001$ \\
\hline
\end{tabular}

\section{Disscussion:-}

Exposed roots resulting from gingival recession, besides being unaesthetic also causes additional problem like dentinal hypersensitivity, pulpal hyperemia, and dental caries. Hence, root coverage has become a very important procedure. There are various technique employed for root coverage procedure such as free gingival autograft, pedicle graft, coronally advanced flap, semilunar flap, subepithelial connective tissue graft, guided tissue regeneration technique and tunnel technique. These techniques employ intrasulcular incisions which causes tissue trauma to the sulcular epithelium which may lead to unfavorable healing and it is also technique sensitive [Singh

AK, Gautam A., 2016]. 
So, in order to overcome the shortcoming of those techniques, a minimally invasive technique called" vestibular incision subperiosteal tunnel access (VISTA) was developed. VISTA approach has a number of advantages for the successful treatment of multiple recession defects. The vertical incision that is given mesial to the defect reduces the possibility of traumatizing the gingiva of the teeth being treated. Also subperiosteal dissection reduces the tension of the gingival margin during coronal advancement and maintaining blood supply to interdental papillae. In VISTA technique, advancement of gingival margin with augmented membrane or graft coronal to CEJ and securing the gingival margin in fixed stable position to prevent relapse in earlier stage of healing gives better results in gingival recession coverage [Reddy Shantipriya et al., 2016].

The subepithelial connective tissue grafts (SCTG), is the gold standard and has achieved the best clinical results in the treatment of localized GRs. It is one of the most studied forms of treatment, as it is highly predictable in terms of exposed root coverage in Miller Class I and II recessions, for both the short and long term. However, this procedure causes discomfort, postoperative pain, and it is associated with a risk of immediate and/or delayed hemorrhage [De Sanctis M et al., 2011].

Other treatment modalities are non-pedicled and pedicled buccal fat pad graft which is adipose tissue formed of a central body and four extensions: buccal, pterygoid, pterygopalatine, and temporal. The PBFP applications are well documented with its advantages by means of its available volume and healing. The main disadvantage of this flap that it cannot reach the anterior regions of the oral cavity, and its use is limited to the posterior areas inside the mouth [Singh J et al., 2010 \& El-Haddad SA El-Shall MA., 2017]. Several reports have been published to describe the PBFPF as a successful and a predictable tool in the treatment of severe GRs at the maxillary teeth posterior to the canines [EI-Haddad SA El-Shall MA., 2017, El Haddad SA et al 2008].

The use of NPBFP to correct contour deformities and to enhance the volume of the recipient sites is widely familiar in the cosmetic surgery [Mazzola RF, Mazzola IC., 2015 \& Tuin AJ et al., 2016]. After various clinical applications in the maxillofacial field, it is now well established that NPBFP can survive and heal very well, so it can be used as an excellent tissue graft in different defects in the oral cavity [Kablan F, 2016]. BFP obtains rich blood supply from the buccal and deep temporal branches of the maxillary artery, transverse facial branches of the superficial temporal artery, and branches of the facial artery. The high success rate of NPBFP may be accounted for by its rich blood supply [Esra Ercan et al., 2016]. Histologically, the transpositioned part of BFP becomes reepithelizied and transforms into parakeratotic stratified squamous epithelium with dense connective tissue without fat cells [Farré-Guasch $\mathbf{E}$ et al., 2010].

The aim of the study was to compare effect of SCTG (group I) versus NPBFP (group II) in treatment of class I and II gingival recession using VISTA technique. Both groups showed statistically significant differences in GR at 3 and 6 months postoperatively in comparison with baseline, while, none of the evaluated clinical parameters differed significantly between the groups at baseline or at any of the assessed postoperative periods.

Both treatment modalities investigated in the present study yielded good mean percentages of root coverage 6 months after surgery. Complete root coverage was observed in $90 \%$ of the cases in group I while $80 \%$ in group II at 6 months after surgery. This outcome agrees with previous studies involving SCTG, which reported mean percentages of root coverage ranging from $60 \%$ to $98.9 \%$ [ Harris RJ, 2002]. This rate was lower than the one reported in other controlled clinical trials which also used SCTG to treat GRs [Bittencourt S et al., 2009]. Such variations in results are common place and may be due to various factors including the clinical experience of the surgeons, periodontal biotype, the healing potentials of the patients, and the anatomical characteristics of their GRs [Cortellini P, Pini Prato G, 2012].

In accordance with our results, Kablan FK. found significant reduction of recession occurred when using fat tissue harvested from the buccal fat pad as a free graft to treat GR with coronlly advanced flap when compared to baseline [Kablan F, 2018].

Owing to the lack of studies involving the relatively new technique of NPBFP, it was not possible to compare the results from the NPBFP group with those of other studies. However, GRs treated via NPBFP exhibited similar results as those treated via SCTG, which is considered the gold standard for the treatment of GRs [Zucchelli G et al., 2014].Therefore, according to our results, the use of NPBFP can be considered a predictable treatment option for Miller class I and II GRs, and we believes that by harvesting NPBFP from both sides (right and left) from the 
patient, NPBFP can provide enough volume to treat multiple GRs and may be efficient to treat full - mouth GRs, and to our knowledge, there is no connective tissue donor site in the oral cavity that can provide the same quantity and ability.

\section{Conclusion:-}

The use of NPBFP may be a valuable procedure for management of recession defects class I and II as SCTG with VISTA technique. This technique can be used successfully in the treatment of multiple gingival recessions as an alternative to previous techniques that result in morbidity associated with donor tissues and scar formation.

\section{References:-}

1. Bittencourt S, Ribeiro EDP, Sallum EA, Sallum AW, Nociti Jr FH, Casati MZ.(2009) Semilunar coronally positioned flap or subepithelial connective tissue graft for the treatment of gingival recession: a 30-month follow-up study. J Periodontol ;80:1076-1082.

2. Cortellini P, Pini Prato G. (2012)Coronally advanced flap and combination therapy for root coverage. Clinical strategies based on scientific evidence and clinical experience. Periodontol 2000;59:158-184.

3. de Castro CH, de Souza LN, Fernandes Santos Melo M.(2015) Use of the buccal fat pad as free graft for closure of oronasal fistula in a cleft palate patient. J Craniofac Surg ;26:e14-6.

4. De Sanctis M, Baldini N, Goracci C, Zucchelli G.(2011) Coronally advanced flap associated with a connective tissue graft for the treatment of multiple recession defects in mandibular posterior teeth. Int $\mathrm{J}$ Periodontics Restorative Dent 2011;31:623-630.

5. Divyanshu Jamwal., Pramod Waghmare., Amita Mali., Rohini Mali., Amit Chaudhari and Nilima Landge. (2017) VESTIBULAR INCISION SUBPERIOSTEAL TUNNEL ACCESS (VISTA) FOR ROOT COVERAGE WITH PLATELET RICH FIBRIN (PRF): A CASE REPORT. International Journal of Recent Scientific Research Research. October; Vol. 8, Issue, 10, pp. 21081-21083.

6. El Haddad SA, Abd El Razzak MY, El Shall M. (2008) Use of pedicled buccal fat pad in root coverage of severe gingival recession defect. J Periodontol ;79:1271-9.

7. El-Haddad SA, El-Shall MA. (2017) Two-year clinical evaluation of pedicled buccal fat pad alone and with emdogain for root coverage of severe gingival recession defects: A case series. Int J Periodontics Restorative Dent ;37:901-7.

8. Esra Ercan, Celal andırl, Cihan Uysal, Bilge Cansu Uzun, Engin Yenilmez.(2016) Treatment of Severe Gingival Recession Using Pedicled Buccal Fat Pad: Histological and Clinical Findings. Clin Exp Health Sci 2016; 6(4): 191-194.

9. Farré-Guasch E, Marti-Pagès C, Hernandez-Alfaro F, Klein-Nulend J, Casals N.(2010) Buccal fat pad, an oral access source of human adipose stem cells with potential for osteochondral tissue engineering: an in vitro study. Tissue Engineering Part C Methods; 16: 1083-94.

10. Harris RJ. (2002) Root coverage with connective tissue grafts: an evaluation of short- and long-term results. J Periodontol ;73:1054-1059.

11. Hürzeler MB, Weng D.(1999) A singl- incision technique to harvest subepithelial connective tissue grafts from the palate. Int J periodontics Restorative Dent Jun;19(3):279-287

12. Jankovic S, Klokkevold P, Dimitrijevic B, Kenney EB, Camargo P.(2012) Use of platelet rich fibrin membrane following treatment of gingival recession: a randomized control clinical trial. Int J Periodontics Restorative Dent.; 32:e41-e50.

13. Kablan F. (2016) The use of buccal fat pad free graft in closure of soft-tissue defects and dehiscence in the hard palate. Ann Maxillofac Surg;6:241-5.

14. Kablan F. (2015)The use of buccal fat pad free graft in regenerative treatment of peri-implantitis: A new and predictable technique. Ann Maxillofac Surg ;5:179-84.

15. Kablan FK. (2018)The reliability of free buccal fat graft for treatment of severe gingival recessions at mandibular and maxillary exposed roots. Ann Maxillofac Surg ;8:281-6.

16. Mazzola RF, Mazzola IC.(2015) History of fat grafting: From ram fat to stem cells. Clin Plast Surg ;42:147-53.

17. Miller PD Jr.(1985) A classification of gingival recession . Int J Perio Rest Dent ;5(2):9-13.

18. Reddy S, Prasad MJS, Agnihotri J, Amudha D, Singh S, Krishnanand P. (2013)Management of multiple recession defect using modified coronally advanced flap alone or with PRF. Int J Health Sci Res;3:133-138.

19. Reddy Shantipriya, Prasad MGS, Nirjhar Bhowmik, Savita Singh, Huzaifa Rashid Pandit and Vimal SK. (2016)Vestibular incision subperiosteal tunnel access (VISTA) with platelet rich fibrin (PRF) and connective 
tissue graft (CTG) in the management of multiple gingival recession- A case series. International Journal of Applied Dental Sciences; 2(4): 34-37.

20. Saurav Panda, Massimo Del Fabbro, Anurag Satpathy, Abhaya Chandra Das.(2016) Pedicled buccal fat pad graft for root coverage in severe gingival recession defect Journal of Indian Society of Periodontology., IP: 111.93.217.218.

21. Singh AK, Gautam A.(2016) Platelet-rich fibrin reinforced periosteal pedicle graft with vestibular incision subperiosteal tunnel access technique for the coverage of exposed root surface. J Interdiscip Dentistry; 6:33-8.

22. Singh J, Prasad K, Lalitha RM, Ranganath K. (2010) Buccal fat pad and its applications in oral and maxillofacial surgery: a review of published literature (february) 2004 to (July) 2009. Oral Surg Oral Med Oral Pathol Oral Radiol Endod ; 110: 698-705.

23. The American Academy of Periodontology.(2001) Gingival recession. In: Recession, eds Glossary of periodontal terms. 4th ed. American Academy of Periodontology: Chicago, Illinois:44.

24. Tuin AJ, Domerchie PN, Schepers RH, Willemsen JC, Dijkstra PU, Spijkervet FK, et al.(2016) What is the current optimal fat grafting processing technique? A systematic review. J Craniomaxillofac Surg;44:45-55

25. Zadeh HH. (2011) Minimally invasive treatment of maxillary anterior gingival recession defects by vestibular incision subperiosteal tunnel access and platelet-derived growth factor BB. Int J Periodontics Restorative Dent.; 31:653-660.

26. Zucchelli G, Mounssif I, Mazzotti C, Stefanini M, Marzadori M, Petracci E, et al.(2014) Coronally advanced flap with and without connective tissue graft for the treatment of multiple gingival recessions: a comparative short- and long-term controlled randomized clinical trial. J Clin Periodontol;41:396-403. 